\title{
Arsenic transfer along the soil -sclerotiu-stroma chain in Chinese cordyceps and the related health risk assessment
}

\author{
YuGuo Liu ${ }^{\text {Equal first author, } 1}{ }^{,}$Ming Shi ${ }^{\text {Equal first author, } 1}{ }^{1}$ XiaoShan Liu ${ }^{1}$, JinYing Xie ${ }^{1}$, RunHuang Yang ${ }^{1}$, QiaoWei Ma ${ }^{1}$, \\ LianXian Guo ${ }^{\text {Corresp. } 1}$ \\ ${ }^{1}$ Dongguan Key Laboratory of Environmental Medicine, School of Public Health, Guangdong Medical University, Dongguan, China \\ Corresponding Author: LianXian Guo \\ Email address: glx525@gdmu.edu.cn
}

Background. Chinese cordyceps (Lepidoptera: Ophiocordyceps sinensis) is a larval-fungus complex. The concentration and distribution of arsenic (As) may vary during the stroma (ST) germination process and between the sclerotium (SC) and the ST. The soil-to-Chinese cordyceps system is an environmental arsenic exposure pathway for humans. We studied the As concentration in the soil, the SC, and the ST of Chinese cordyceps, and performed a risk assessment.

Methods. Soil and Chinese cordyceps samples were collected from the Tibetan Plateau in China. The samples were analyzed for the total As concentration and As species determination, which were conducted by inductively coupled plasma mass spectrometry (ICP-MS) and HPLC-ICP-MS, respectively.

Results. The concentration of total As in the soil was much higher than in SC and ST. The major As species in the soil was inorganic iAs ${ }^{\vee}$. In SC and ST, organic As was predominant, and the majority of As was an unknown organic form. There are significant differences in the As distribution and composition in soil, SC, and ST. Our risk assessment indicated that chronic daily ingestion was higher than inhalation and dermal exposure in children and adults. The hazard index $(H I)$ of the non-carcinogenic and cancer risks $(C R)$ for human health were $H I \leq 1$ and $C R<1 \times 10^{-4}$, respectively.

Conclusion. The Chinese cordyceps possesses highly-efficient detoxifying characteristics and has a significant role in As transformation during its life cycle. We found that the levels of As in soils from the habitat of Chinese cordyceps were higher than the soil background values in China, but the probability for incurring health risks remained within the acceptable levels for humans. 


\section{Arsenic transfer along the soil-sclerotiu-stroma chain in Chinese cordyceps}

\section{2 and the related health risk assessment}

4 YuGuo Liu ${ }^{\dagger}$, Ming Shi ${ }^{\dagger}$, XiaoShan Liu, JinYing Xie, RunHuang Yang, QiaoWei Ma, and 5 LianXian Guo

6 Dongguan Key Laboratory of Environmental Medicine, School of Public Health, Guangdong

7 Medical University, Dongguan, China

$8 \dagger$ These authors contributed equally to this work.

9

10 Corresponding author

11 LianXian Guo, glx525@gdmu.edu.cn

12

13

14

15

16 


\section{ABSTRACT}

32 Background. Chinese cordyceps (Lepidoptera: Ophiocordyceps sinensis) is a larval-fungus 33 complex. The concentration and distribution of arsenic (As) may vary during the stroma 34 (ST) germination process and between the sclerotium (SC) and the ST. The soil-to-Chinese cordyceps system is an environmental arsenic exposure pathway for humans. We studied the As concentration in the soil, the SC, and the ST of Chinese cordyceps, and performed a risk assessment.

Methods. Soil and Chinese cordyceps samples were collected from the Tibetan Plateau in China. The samples were analyzed for the total As concentration and As species determination, which were conducted by inductively coupled plasma mass spectrometry 41 (ICP-MS) and HPLC-ICP-MS, respectively.

42 Results. The concentration of total As in the soil was much higher than in SC and ST. The 43 major As species in the soil was inorganic iAs ${ }^{\mathrm{V}}$. In SC and ST, organic As was 44 predominant, and the majority of As was an unknown organic form. There are significant differences in the As distribution and composition in soil, SC, and ST. Our risk assessment indicated that chronic daily ingestion was higher than inhalation and dermal exposure in children and adults. The hazard index $(H I)$ of the non-carcinogenic and cancer risks $(C R)$

48 for human health were $H I \leq 1$ and $C R<1 \times 10^{-4}$, respectively.

49 Conclusion. The Chinese cordyceps possesses highly-efficient detoxifying characteristics and has a significant role in As transformation during its life cycle. We found that the 51 levels of As in soils from the habitat of Chinese cordyceps were higher than the soil background values in China, but the probability for incurring health risks remained within

53 the acceptable levels for humans.

Keywords Chinese cordyceps, Arsenic, Soil, Health risk

\section{INTRODUCTION}


58 Tibetan Plateau. The Latin name of this fungus has recently been debated. In this article, we use

59 the phrase "Chinese cordyceps" refer to the fungus-caterpillar complex (Dong et al., 2016). The

60 Chinese cordyceps goes through two stages to complete its life cycle: teleomorph and anamorph.

61 The ascospores erupt from mature stroma and form directly into conidia or mycelium in the

62 summer. The conidia or mycelium found in deeper soils in autumn can infect a host (Zhang et al.,

63 2012). Similarly, larvae from the host Thitarodes (Lepidoptera: Hepialidae) infiltrate the soil

64 after incubating from the eggs scattered on the grassland (Fig. 1A) and safely reside in the roots

65 of their preferred substrates throughout the long-lasting larval stage (Fig. 1B) (Chen et al., 2009).

66 After developing through four to five instars, which takes approximately two to three years, the

67 larvae may become infected by the fungus in the soil around June (Fig. 1D) (Zou et al., 2010).

68 The larvae then become the fungal host and their interiors are gradually filled with thread-like

69 hyphae, which forms the caterpillar-shaped sclerotium (SC) (the so-called winter-worm; Fig. 1E)

70 in the winter. The sclerotium germinate from the head of the winter-worm in the spring when the

71 frozen soil thaws and grow into stroma (ST) (the so-called summer-grass; Fig. 1F) over

72 approximately 2 months. The stroma mature and disperse millions of spores (Fig. 1C) initiating

73 the next hostile takeover (Guo et al., 2017).

74 Chinese cordyceps have a long history in traditional Chinese medicine. Its pharmaceutical

75 functions are reported to have included antitumor, anti-inflammatory, antioxidant, anti-

76 hyperglycemia, anti-apoptosis, immunoregulatory, and hepatoprotective effects (Qi et al., 2014;

77 Liu et al., 2015). However, the concentration of As (total As: 4.4-9.0 mg/kg) in Chinese

78 cordyceps was at least three times greater than the reference value of $1 \mathrm{mg} / \mathrm{kg}$ (NHFPC, 2014),

79 which was disclosed by the China Food and Drug Administration (CFDA) (CFDA, 2016a).

80 These levels have raised concerns regarding the health of functional foods and the promotion of 
81 functional foods, specifically Chinese cordyceps, was suspended (CFDA, 2016b). The report

82 badly affected the industrial chain of Chinese cordyceps (Wang et al., 2016).

83 Arsenic is an environmental contaminant able to disperse and enter humans through the food 84 chain. It is considered to be the most concerning hazardous material in the world due to its toxicity (Styblo et al., 2000). The toxic effect of arsenic depends on its species. Inorganic arsenic

86 (iAs) is carcinogenic to people, as are trivalent iAs (arsenite, As ${ }^{\mathbb{I I}}$ ) and pentavalent iAs (arsenate,

$87 \mathrm{iAs}^{\mathrm{V}}$ ), which are widely present in the soil and water (Huang and Ke, 2004). When iAs transfer 88 into organisms along the food chain, it would be transformed into organic arsenic species (oAs) by the organisms. Monomethylarsonic acid $\left(\mathrm{MMA}^{\mathrm{V}}\right)$ and dimethylarsinic acid $\left(\mathrm{DMA}^{\mathrm{v}}\right)$ are the 90 major metabolic products of iAs, which have lower toxicity than iAs. The subsequent 91 metabolites, including organic As compounds: arsenocholine, arsenobetaine (AsB), various 92 arsenolipids, and arsenosugars, are typically considered nontoxic (Hua et al., 2011; Styblo et al., 93 2000). Thus, the As transforming processes in organisms are generally detoxifying for iAs. 94 Moreover, some trivalent metabolites, including monomethylarsonous acid (MMA ${ }^{\mathrm{III}}$ ) and 95 dimethylarsenic acid (DMA $\left.{ }^{\mathrm{III}}\right)$ in animals and human cells, or arsenic-containing hydrocarbons such as $\mathrm{C}_{17} \mathrm{H}_{37} \mathrm{AsO}, \mathrm{C}_{19} \mathrm{H}_{41} \mathrm{AsO}$ and $\mathrm{C}_{23} \mathrm{H}_{37} \mathrm{AsO}$ in seafoods, have been shown to be cytotoxic 97 (Arroyo-Abad et al., 2010; Meyer et al., 2014). In our previous work (Guo et al., 2018b), we 98 found that unknown organic As species (oAsU), which were considered to be arsenosugars, 99 comprise a large proportion of the total As in Chinese cordyceps.

100 Unlike other mushrooms in which only the stroma or fruiting body is consumed (Larsen et al., 101 1998; Kuehnelt et al., 1997), the Chinese cordyceps is a larval-fungus complex, and the 102 sclerotium is the complex of the host larva (substrate) and mycelium of the fungus, while the 103 stroma is purely composed of the fungus (Zhang et al., 2012). In this context, our study is 
104 designed to determine the arsenic species and its distribution in the soil habitat-sclerotium-

105 stroma complex. We studied the risk assessment of As in the soils around the habitat of the

106 Chinese cordyceps on the Qinghai-Tibet Plateau, which has a greater environmental background

107 value of As than other regions in China.

108 MATERIALS AND METHODS

109 Sample collection and preparation

110 We selected three sites from the endemic areas in Shergyla Mountain, Tibet for this study. Site A

111 was located at $29^{\circ} 36^{\prime} \mathrm{N}, 9^{\circ} 36^{\prime} \mathrm{E}$; Site B was located at $29^{\circ} 35^{\prime} \mathrm{N}, 94^{\circ} 36^{\prime} \mathrm{E}$; and Site C, was

112 located at $35^{\circ} 14^{\prime} \mathrm{N}, 91^{\circ} 48^{\prime} \mathrm{E}$. We took fifteen soil samples from the $10-20 \mathrm{~cm}$ topsoil and twenty

113 Chinese cordyceps samples about $0.3 \mathrm{~g}$ each from each sampling site in mid-July 2017. The

114 samples were kept in an icebox and were transported to the laboratory.

115 In the laboratory, these samples were freeze dried. The Chinese cordyceps samples were

116 divided into two subsamples: SC and ST. ST was light and thin compared with SC, and each of

117 the ten ST subsamples were combined to form a batch sample. Each of the five SC subsamples

118 were combined to form a batch sample. The twenty Chinese cordyceps samples collected from

119 each sampling spot were divided into four batches of sclerotium samples and two batches of

120 stroma samples, which were named $\mathrm{SC}_{\mathrm{A} / \mathrm{B} / \mathrm{C}}$ and $\mathrm{ST}_{\mathrm{A} / \mathrm{B} / \mathrm{C}}$ according to sampling sites. Soil samples

121 were ground into powders with a grain size of less than 150 mesh. Every five powdered soil

122 samples were combined into one batch and named $\mathrm{A} / \mathrm{B} / \mathrm{C}$ according to sampling sites.

\section{Sample digestion}

$124 \quad 0.1 \mathrm{~g}$ of each pre-dried sample was digested with concentrated nitric acid (16 mol/L) using the

125 high-temperature and microwave-assisted methods to determine the total As concentration in SC

126 and ST. The digestion methods followed that of our earlier study (Guo et al., 2018b). To 
127 determine the As speciation, $1 \mathrm{~g}$ of the sample powder was digested with $20 \mathrm{~mL} 0.15 \mathrm{~mol} / \mathrm{L}$

$128 \mathrm{HNO}_{3}$ at $90{ }^{\circ} \mathrm{C}$ using a water bath for 12 hours (Guo et al., 2018b). The sample was cooled to

129 room temperature and all of the digested product was centrifuged for $15 \mathrm{~min}$ at the speed of 7104

$130 \mathrm{~g}$. The collected supernatant was filtered through a sieve with a mesh aperture of $0.22 \mu \mathrm{m}$ and

131 kept in cold storage until analysis.

132 Approximately $0.1 \mathrm{~g}$ of each powdered sample was blended with a mixed solution of 133 hydrochloric acid at $12 \mathrm{~mol} / \mathrm{L}$ and concentrated nitric acid at $16 \mathrm{~mol} / \mathrm{L}$ with the volume ratio of

$1343: 1$ to determine the total As concentration in the soil. Digestion was performed according to the 135 standard method, HJ 803-2016 (MEPP 2016). Different As species were extracted according to 136 the method used by Thomas (1997). Briefly, $10 \mathrm{~mL} 1 \mathrm{~mol} / \mathrm{L}$ phosphoric acid $\left(\mathrm{H}_{3} \mathrm{PO}_{4}\right)$ was added 137 into $0.2 \mathrm{~g}$ pre-dried sample, processed, and cooled in a microwave. The extract was filtered and 138 diluted with distilled water and prepared for analysis.

139 Arsenic determination of sample

140 The total As was measured by ICP-MS (Agilent 7800, Santa Clara, CA, USA). The separation of

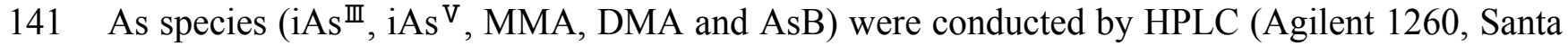
142 Clara, CA, USA) and the separated As species were determined by ICP-MS. Based on our 143 previous study (Guo et al., 2018b), the iAs ${ }^{\mathrm{III}}$ could not be separated from the other arsenic 144 species. To determine the level of $\mathrm{iAs}{ }^{\mathrm{III}}, 1 \mathrm{~mL} \mathrm{H}_{2} \mathrm{O}_{2}$ was added into the extraction to fully 145 oxidize the $\mathrm{iAs}{ }^{\mathrm{III}}$ to $\mathrm{iAs}^{\mathrm{V}}$ and the arsenic species were analyzed before (Figs. $2 \mathrm{~B}$ to $2 \mathrm{C}, 2 \mathrm{~F}$ ) and 146 after (Figs. 2D to $2 \mathrm{E}, 2 \mathrm{G}) \mathrm{H}_{2} \mathrm{O}_{2}$ was added. The $\mathrm{iAs}{ }^{\mathrm{III}}$ was calculated by subtracting the level of $147 \mathrm{iAs}{ }^{\mathrm{V}}$ before addition to $\mathrm{H}_{2} \mathrm{O}_{2}$ from the level of $\mathrm{iAs}{ }^{\mathrm{V}}$ after addition to $\mathrm{H}_{2} \mathrm{O}_{2}$. 
148 Each test was performed in triplicate. The concentrations of total As and As species were

149 quantified using calibration curves, which was made with standard samples (National Institute of

150 Metrology, Beijing, China).

151 The precision of our results was tested by a blank reagent and the Chinese national standard

152 for the green Chinese onion: GBW10049 (GSB-27) and the yellow croaker: GBW08573. Linear

153 responses ranged between 0.5 and $500 \mu \mathrm{g} / \mathrm{L}$ for the total As determination and between 0.2 and

$154300 \mu \mathrm{g} / \mathrm{L}$ for the As species determination; the correlation coefficients were greater than 0.9997

155 (Table S1). The relative standard deviation (RSD) was less than $10 \%$ (Table S2) and the

156 recovery of these certified reference materials was within the acceptable range (Table S3).

157 Health risk assessment of As in soil

158 Arsenic has been categorized as a chemical carcinogen by USEPA (USEPA, 2011), as well as

159 non-carcinogens for human. Arsenic can migrate into plants and enter the human body through

160 oral ingestion as part of the food chain. The inhalation of soil and dust, and dermal contact are

161 also exposure pathways for humans. Therefore, to comprehensively assess arsenic exposure all

162 three exposure pathways are taken into consideration.

163 According to the model of human health evaluation by the United States Environment

164 Protection Agency (USEPA) (USEPA, 1989), the average daily doses $(A D D, \mathrm{mg} /(\mathrm{kg} \cdot \mathrm{d}))$ through

165 the three exposure pathways (ingestion: $A D D_{\text {ing }}$; inhalation: $A D D_{\text {inh }}$; dermal contact: $A D D_{\text {dermal }}$ )

166 were calculated separately as follows:

$167 A D D_{\text {ing }}=C \times \frac{\operatorname{IngR} \times E F \times E D}{B W \times A T} \times 10^{-6}$

168

$169 A D D_{i n h}=C \times \frac{I n \mathrm{~h} R \times E F \times E D}{P E F \times B W \times A T}$

170

$171 A D D_{\text {dermal }}=C \times \frac{S A \times A F \times A B F \times E F \times E D}{P E F \times B W \times A T} \times 10^{-6}$ 
173 where $C(\mathrm{mg} / \mathrm{kg})$ is the concentration of total As in soil, $E F$ (days/year) is the exposure

174 frequency, $E D$ (years) is the exposure duration, $B W(\mathrm{~kg})$ is the body weight, $A T$ (days) is the

175 average time, $P E F\left(\mathrm{~m}^{3} / \mathrm{kg}\right)$ is the particular emission factor, $S A\left(\mathrm{~cm}^{2}\right)$ is the surface area of

176 exposed skin, $A F\left(\mathrm{mg} / \mathrm{cm}^{2}\right)$ is the skin adherence factor, $A B F$ is the absorption factor, IngR

$177(\mathrm{mg} / \mathrm{d})$, and $\operatorname{Inh} R\left(\mathrm{~m}^{3} /\right.$ days $)$ is the ingestion rate and inhalation rate, respectively. The parameters

178 for children and adults are shown in Table S4 and refer to the Chinese assessment guidelines for

179 an environmental site (MEPP, 2014) and U.S. exposure factors handbook (USEPA, 2011).

180 The hazard quotient $(H Q)$ was calculated separately as follows:

$181 H Q=\frac{A D D}{R f D}$

$182 H I=\sum H Q_{i}$

183 where $R f D$ is the non-carcinogenic reference dose for As $(\mathrm{mg} /(\mathrm{kg} \cdot \mathrm{d}))$; the values through

184 ingestion, inhalation, and dermal contact are: $3.0 \times 10^{-4}, 1.5 \times 10^{-5}$, and $3.0 \times 10^{-4}$, respectively

185 (MEPP, 2014; USEPA, 2013; Liu et al., 2008). HI is the total exposure hazard index. If $H Q$ or

$186 H I<1$, there is no concern for non-carcinogenic effects, whereas potential non-carcinogenic

187 risks may occur in cases where $H Q$ or $H I>1$.

188 Carcinogenic risk $(C R)$ was calculated as follows:

$189 C R=A D D_{\text {ing/inh/dermal }} \times S F$

$190 \quad C R_{T}=\sum C R$

191 where $S F$ is the slope factor of As and the values through ingestion, inhalation, and dermal

192 contact is: $1.5,4.3 \times 10^{-3}$, and 1.5, respectively (USEPA, 2011; MEPP, 2014; USEPA, 2013; Liu

193 et al., 2008). $C R_{T}$ is the sum of $C R$ for the three pathways. The probability of cancer risk for

194 humans over a lifetime is characterized by $C R$ with an acceptable range from $1.0 \times 10^{-6}$ to $1.0 \times 10^{-}$ 
1954 . If $C R<1.0 \times 10^{-6}$, which suggests no significant effect on human beings; $C R>1.0 \times 10^{-4}$ is

196 likely to be harmful to humans.

197 Statistical analysis

198 Data were analysed using Microsoft Excel 2013 (Microsoft, Redmond, WA, USA) and SPSS

19913.0 (IBM, Chicago, IL, USA). The levels of As were calculated as the means \pm standard 200 deviations (SD). Wilcoxon and Kruskal-Wallis tests were used to check the significance in the 201 concentrations of total As and As species among different samples. The significant difference 202 was considered to be $p<0.05$.

\section{RESULTS}

204 Total arsenic concentration

205 The concentrations of total As in the soil samples are presented in Table 1. The highest level of 206 total As was shown in Site A (16.31 mg/kg) and the lowest level was shown in Site B (13.03 $207 \mathrm{mg} / \mathrm{kg}$ ). The mean concentrations of total As in Sites A, B and C were 1.5, 1.2, and 1.4 times 208 higher than the background soil values in China, respectively (Wei et al., 1991).

209 The concentrations of total As in SC and ST are reported in Table 1. The mean concentration 210 of total As in SC from the study area was between 4.64 and $5.68 \mathrm{mg} / \mathrm{kg}$. By comparing the 211 reference value of total As in functional foods (NHFPC, 2014), it was observed that total As in 212 SC was about five times higher. The mean level of total As in ST ranged from 0.82 to 1.13 $213 \mathrm{mg} / \mathrm{kg}$, which was close to the reference value (NHFPC, 2014).

214 The concentration of total As decreased as follows: soil $>\mathrm{SC}>\mathrm{ST}(p<0.01$, Wilcoxon and 215 Kruskal-Wallis tests, Table S5).

216 Arsenic species 
217 The concentrations of different As species in soil samples are shown in Table 1 (the

218 chromatograms are shown in Figs. $2 \mathrm{~F}$ to $2 \mathrm{G})$. The results showed that inorganic As was

219 abundant in Sites $\mathrm{A}, \mathrm{B}$, and $\mathrm{C}$, and $\mathrm{iAs}{ }^{\mathrm{V}}$ was significantly higher than iAs ${ }^{\mathrm{III}}$ (Table S6). The

220 concentration of organic As was significantly lower than inorganic As (Table S6), and small

221 amounts of AsB were detected in organic As.

222 The concentrations of different As species in the SC and ST samples were presented in Table

2231 (the chromatograms are shown in Fig. 2). Under the $\mathrm{H}_{2} \mathrm{O}_{2}$ treatment, most of the As species in

224 the large peak area were not oxidized to $\mathrm{iAs}^{\mathrm{V}}$ (Figs. 2D to 2E), which proved that the major

225 overlapped peak was not the toxic iAs ${ }^{\text {III }}$ but various unknown organic As species (oAsU).

226 However, it was not possible to evaluate their definite compounds and structures due to the lack

227 of appropriate standards.

228 Inorganic As were in the minority in the SC samples, in which iAs ${ }^{\mathrm{III}}$ was significantly higher

229 than $\mathrm{iAs}^{\mathrm{V}}$ (Table S6). The concentration of organic As was significantly higher when compared

230 with inorganic As. Among these organic As, oAsU was abundant, while DMA and MMA were

231 almost negligible. In the ST samples, inorganic As were also in the minority, while iAs ${ }^{\mathrm{V}}$ was

232 significantly higher than iAs ${ }^{\mathrm{III}}$ (Table S6). The concentration of organic As was significantly

233 higher than inorganic As (Table S6). Among the detected organic As species, oAsU was the

234 predominant species and AsB and DMA were detected in minor amounts in some samples.

\section{Hazard assessment of the soil}

236 The calculated average daily doses $(A D D)$ for non-carcinogens and carcinogens are summarized

237 in Tables 2 and 3. The $A D D$ decreased through different exposure pathways in the following 238 order: $A D D_{\text {ing }}>A D D_{\text {inh }}>A D D_{\text {derm }}$, indicating that ingestion is the major exposure pathway. Chil

239 dren are more vulnerable to toxicity than adults because of the higher $A D D$. The results of 
240 human health risk assessment of As in soil suggested that the potential non-carcinogenic risk was

241 negligible since the $H I$ was less than 1 (Table 4). The cancer risks $(C R)$ for human health were at

242 an acceptable level (total $C R<1 \times 10^{-4}$ ) (Table 4).

243

244 DISCUSSION

245 Arsenic transfer chain during Chinese cordyceps formation

246 As a special organism growing in the Tibetan Plateau (Li et al., 2008), Chinese cordyceps is

247 considered to be a consumer and a de-composer in the food-chain. Our study revealed the total

248 As abundance in the soil of the habitat of the Chinese cordyceps was higher than the average

249 overall abundance. Furthermore, inorganic As accounted for the majority of total As in soil. The

250 original organisms in this soil ecosphere have developed detoxifying strategies to survive and

251 adapt to the toxic circumstances. Although the As transfer chain and corresponding metabolism

252 from the soil to Chinese cordyceps have not been investigated, previous research on plants (Zhao

253 et al., 2009; Lomax et al., 2012), animals (Healy et al., 1998), and fungi (Gonzálvez et al., 2009;

254 Soeroes et al., 2005; Chang et al., 2019) may explain the complicated delivery and

255 transformation of As as follows: first, through the passive absorption from plants' roots, the

256 original As in the soil is transported and isolated into the plant vacuoles to avoid its toxic effects.

257 During this process, the inorganic As keeps its original speciation because plant cells cannot

258 regulate the methylation of As due to lack of methyltransferase (Zhao et al., 2009; Lomax et al.,

259 2012). The host Thitarodes larvae, which take the plants' tender roots for two to three years as

260 their preferred food (Fig. 1B), first reduce the ingested iAs ${ }^{\mathrm{V}}$ to $\mathrm{iAs}^{\mathrm{II}}$ by their reductase and then

261 methylate iAs ${ }^{\text {III }}$ to low toxic MMA or DMA via methylationase. Subsequently, MMA and DMA

262 are detoxified into other nontoxic As compounds. Notably, fungus also contain methylationase 
263 for the methylation (Tang et al., 2016; Zhang et al., 2017). We found that both the As

264 concentration and speciation were significantly different between the soil environment and SC.

265 The larva-fungi union may have highly efficient detoxifying mechanisms through which the

266 inorganic As ingested by Thitarodes larvae had been turned into organic As.

267 It was not possible to accurately evaluate the effect of Chinese cordyceps on As 268 transformation based on changes in the SC since SC was the complex of host larvae and 269 mycelium. Thus, we focused on the concentration and distribution of As across the ST, which 270 grew only from the Chinese cordyceps without any interference from the host tissue. Here we

271 found that the level of total As from SC to ST has been reduced greatly. The level of iAs ${ }^{\mathrm{III}}$ was

272 significantly higher than that of $\mathrm{iAs}^{\mathrm{V}}$ in the SC, but was the opposite in the ST. The results 273 provided strong evidence that although the host larvae ingested large amounts of toxic iAs ${ }^{\text {III }}$ from 274 the soil due to iAs ${ }^{\mathrm{III}}$ solubility (Andrahennadi and Pickering, 2008), Chinese cordyceps can turn 275 substantial parts into low toxic iAs ${ }^{\mathrm{V}}$ to prevent toxicity to offspring (ascospores in ST).

276 The cultivation of wild Chinese cordyceps, which occurred from Thitarods in the habitat's

277 natural soil has not been successful because the occurrence mechanism has been unknown.

278 Artificial laboratory cultivation was based on the cultivated Thitarods fed with prepared feed

279 containing a low As background, and its life span of six months was much shorter than wild 280 Chinese cordyceps (two to three years). Our previous study (Guo et al., 2018a) compared the 281 total As and As species in wild Chinese cordyceps and cultivated Chinese cordyceps. The 282 cultivated Chinese cordyceps were bred under artificial circumstance with trace As in place of 283 the high concentrations of As, which occur naturally on the Tibetan Plateau. Our results 284 showed that As concentration in the cultivated Chinese cordyceps was much lower than that in 285 wild Chinese cordyceps. This finding provided important evidence that the species and As level 
286 were affected by the comprehensive function of soils, host larvae, and Chinese cordyceps fungus

287 for wild Chinese cordyceps. It may be inferred, based on the previous study and the results of

288 this experiment, that unlike Laccaria amethystea (Larsen et al., 1998) and Collybia butyracea

289 (Kuehnelt et al., 1997) which can accumulate As, Chinese cordyceps can reduce As.

290 Arsenic concentration in soil and health risk assessment

291 We found that the total As concentration in soil samples measured by ICP-MS was much higher 292 than the sum of the five As species measured by HPLC-ICP-MS. The difference between the two 293 was unextracted arsenic ores (Liu et al., 2018). Therefore, inorganic arsenic was the 294 predominant form found in the soil and so we took the concentration of total As to assess the 295 potential risk posed by soil arsenic. A previous study reported that the soil's As level in Lhasa 296 was higher than that in our tested sites (Cheng et al., 2014) and the elevated As concentration 297 may be related to transportation pollutants in addition to the local background values.

298 Arsenic can exist in almost all environmental media, especially in the soil. It can accumulate 299 in plants and eventually sneak into the body through the food chain (Wei et al., 2016; Tsuda and 300 Babazono, 1992). Animal husbandry and the dairy industry have long occupied the important 301 position in the local economy where this study was conducted. Arsenic can pose significant 302 health risks through the soil-plants-food-human pathway. However, there was no serious threat 303 to human health based on our results, although As geological background value was higher than 304 that in China. It is worth noting that children were generally more susceptible than adults, which 305 is consistent with many other studies (Chen et al., 2019; Li et al., 2018). However, due to the 306 toxicity variations of As species, further studies should focus on the potential risk caused by toxic As species rather than the total As. 
309 CONCLUSIONS

310 We found that the distribution and species of As were varied among the habitat soil, SC, and

311 ST, suggesting that Chinese cordyceps was not an As-accumulating fungus, as traditionally

312 believed. In addition, we explained the process of arsenic degradation and translocation. Overall,

313 this study provides a new insight into the detoxification mechanism of Chinese cordyceps under

314 high As stress and can be beneficial to the revival of the Chinese cordyceps-dependent industry.

315 Our risk assessment found that there was little risk for humans caused by As in the high

316 geological background area of Qinghai-Tibet Plateau. In order to provide more evidence, there

317 should be additional research to determine the potential risk caused by different arsenic species.

318

319

320 Funding

321 This work was supported by the Natural Science Foundation of Guangdong Province (No.

322 2018A030313094, 2020A151501457), the Social Science and Technology Development

323 Project of Dongguan (No. 20185071521641), the Public Health and Preventive Medicine

324 Discipline Development Funds of Guangdong Medical University in 2020 (No. 4SG20003G),

325 the Talents Recruitment Program of Guangdong Medical University (No. 4SG19003Gd), and the

326 Science and the Technology Key Project of Zhangiiang (No. 2017B01233).

327

328 Competing Interests

329 The authors declare there are no competing interests.

330

331 REFERENCES 
332 Andrahennadi R, Pickering IJ. 2008. Arsenic accumulation, biotransformation and Iocalisation in bertha

333 armyworm moths. Research Paper 5: 413-419 DOI 10.1071/EN08065.

334 Arroyo-Abad U, Mattusch J, Mothes S, Möder M, Wennrich R, Maria P, Gonzalez E, Matysik FM.

335 2010. Detection of arsenic-containing hydrocarbons in canned cod liver tissue. Talanta 82(1): 38-43

336 DOI 10.1016/j.talanta.2010.03.054

337 Chang WD, Bao CJ, Li X, Sun LP. 2019. Research progress in the enrichment of mercury and arsenic by

338

339

340

341

342 edible fungi. Science and Technology of Food Industry 9:374-380

DOI 10.13386/jissn1002-0306.2017.09.064.

Chen D, Yuan JP, Xu SP, Zhou XG, Zhang Y, Xu XM, Zou ZW, Zhang GR, Wang JH. 2009. Stable carbon isotope evidence for tracing the diet of the host Hepialus larva of Cordyceps sinensis in the Tibetan Plateau. Science China Earth Sciences 52(5):655-659 DOI 10.1007/s11430-009-0068-1.

343 Chen YF, Xu JR, Duan XL, Cao SZ, Sun SW, Kang YJ. 2019. Health risks of cumulative oral exposure to 344 heavy metals for children living around a coking enterprise. China Environmental Science 39(11):48654874 DOI 10.19674/j.cnki.issn1000-6923.2019.0568.

346

Cheng HX, Li K, Li M, Yang K, Liu F, Cheng XM. 2014. Geochemical background and baseline value of chemical elements in urban soil in China. Earth Science Frontier 21(3):265-306 DOI 10.13745/j.esf.2014.03.028.

Dong CH, Li WJ, Li ZZ, Yan WJ, Li TH, Liu XZ. 2016. Cordyceps industry in China: current status, challenges and perspectives-Jinhu declaration for Cordyceps industry development. Mycosystema 35(1):115 DOI 10.13346/j.mycosystema.150207.

Gonzálvez A, Llorens A, Cervera ML, Armenta S, De la Guardia M. 2009. Non-chromatographic 353 speciation of inorganic arsenic in mushrooms by hydride generation atomic fluorescence spectrometry. Food Chemistry 115(1):360-364 DOI 10.1016/j.foodchem.2008.11.088.

Guo LX, Hong YH, Zhou QZ, Zhu Q, Xu XM, Wang JH. 2017. Fungus-larva relation in the formation of Cordyceps sinensis as revealed by stable carbon isotope analysis. Scientific Reports 7(1):7789-7793 DOI 10.1038/s41598-017-08198-1.

Guo LX, Zhang GW, Li QQ, Xu XM, Wang JH. 2018a. Novel arsenic markers for discriminating wild and cultivated Cordyceps. Molecules 23(11):2804-2819 DOI 10.3390/molecules23112804.

Guo LX, Zhang GW, Wang JT, Zhong YP, Huang ZG. 2018b. Determination of arsenic species in Ophiocordyceps sinensis from major habitats in China by HPLC-ICP-MS and the edible hazard assessment. Molecules 23(5):1012-1026 DOI 10.3390/molecules23051012. metabolites in human bladder cancer EJ-1 cells. Chemical Research in Toxicology 24(9):1586-1596 DOI $10.1021 / \mathrm{tx} 200291 \mathrm{p}$.

Huang CS, Ke QD, Costa M, Shi XL. 2004. Molecular mechanisms of arsenic carcinogenesis. Molecular and Cellular Biochemistry 255(1-2):57-66 DOI 10.1023/b:mcbi.0000007261.04684.78. 
368 CFDA (China Food and Drug Administration). 2016a. Consumption Tips on Cordyceps sinensis Products.

369 Available at https://www.nmpa.gov.cn/directory/web/nmpa/yaopin/ypjgdt/20160204190401258.html

370 (accessed 4 February 2016).

371 CFDA. 2016b. Notice on the Suspension of All the Pilot Work on Cordyceps sinensis for Health Food.

372 Available at http://www.cfda.com.cn/NewsDetail.aspx?id=86276 (accessed 7 March 2016).

373 Kuehnelt D, Goessler W, Irgolic KJ. 1997. Arsenic compounds in terrestrial organisms I: Collybia maculata,

374 Collybia butyracea and Amanita muscaria from arsenic smelter sites in Austria. Applied Organometallic

375 Chemistry 11(4):289-296

376 DOI 10.1002/(SICI)1099-0739(199704)11:4<289::AID-AOC582>3.0.CO;2-1.

377 Larsen EH, Hansen M, Gössler W. 1998. Speciation and health risk considerations of arsenic in the edible

378 mushroom Laccaria amethystina collected from contaminated and uncontaminated locations. Applied

379 Organometallic Chemistry 12(4):285-291

380 DOI 10.1002/(SICI)1099-0739(199804)12:4<285::AID-AOC706>3.0.CO;2-\%23.

381 Li CL, Kang SC, Wang XP, Ajmone-Marsan F, Zhang Q. 2008. Heavy metals and rare earth elements (REEs) in soil from the Nam Co Basin, Tibetan Plateau. Environmental Geology 53(7):1433-1440 DOI 10.1007/s00254-007-0752-4.

Li LF, Zhu CX, Zeng XB, Li HN, Ye J, Li F, Wu CX. 2018. Accumulation characteristics of heavy metals in greenhouse soil and vegetables in Siping City, Jilin Province. Environmental Science 39(6):2936-2943 DOI 10.13227/j.hjkx.201710154.

Liu GN, Chen M, Li WQ, Gong WW. 2018. A critical review on the speciation and development of sequential extraction procedures for arsenic in soils. Journal of Agro-Environment Science 37(12):26292638 DOI 10.11654/jaes.2018-0544.

Liu Q, Wang J, Shi YX, Zhang YY, Wang QH. 2008. Health risk assessment on heavy metals in soil based on GIS-A case study in Cixi city of Zhejiang Province. Chinese Journal of Soil Science 39(3):634-640 DOI 10.19336/j.cnki.trtb.2008.03.035.

Liu Y, Wang JH, Wang W, Zhang HY Zhang XL, Han CC, Guo JY. 2015. The chemical constituents and pharmacological actions of Cordyceps sinensis. Evidence-Based Complementary and Alternative Medicine 57:50-63 DOI 10.1155/2015/575063.

Lomax C, Liu WJ, Wu LY, Xue K, Xiong JB, Zhou JZ, Mcgrath SP, Meharg AA, Miller AJ, Zhao FJ. 2012. Methylated arsenic species in plants originate from soil microorganisms. New Phytologist 193(3):665672 DOI 10.1111/j.1469-8137.2011.03956x. toxicological characterisation of three arsenic-containing hydrocarbons. Metallomics 6(5):1023-1033 DOI $10.1039 / \mathrm{c} 4 \mathrm{mt} 00061 \mathrm{~g}$. for risk assessment of contaminated sites (HJ 25.3-2014). Beijing: China Environmental Science Press. 
404

405

406

407

408

409

410

411

412

413

414

415

416

417

418

419

420

421

422

423

424

425

426

427

428

429

430

431

432

433

434

435

436

437

438

439

MEPP. 2016. Soil and sediment-determination of aqua extracts of 12 metal elements-Inductively Coupled Plasma Mass Spectrometry (HJ 803-2016). Beijing: China Environmental Science Press.

NHFPC (National Health and Family Planning Commission of the People's Republic of China). 2014. National food safety standard health food (GB16740-2014).

Available at http://www.nhc.gov.cn/sps/s3593/201412/d9a9f04bc35f42ecac0600e0360f8c89.shtml (accessed 31 December 2014)

Qi W, Lei W, Yan YB, Zhang Y, Liu S, Cao PC, Fan Y. 2014. Pharmacological study progress of the Cordyceps sinensis. Global Traditional Chinese Medicine 7(3):227-232

DOI 10.3969/j.issn.1674-1749.2014.03.020.

Soeroes C, Kienzl N, Ipolyi I, Dernovics M, Fodor P, Kuehnelt D. 2005. Arsenic uptake and arsenic compounds in cultivated Agaricus bisporus. Food Control 16(5):459-464

DOI 10.1016/j.foodcont.2004.05.007.

Styblo M, Del Razo LM, Vega L, Germolec DR, LeCluyse EL, Hamilton GA, Reed W, Wang C, Cullen WR, Thomas DJ. 2000. Comparative toxicity of trivalent and pentavalent inorganic and methylated arsenicals in rat and human cells. Archives of Toxicology 74(6):289-299 DOI 10.1007/s002040000134.

Tang Z, Lv YL, Chen F, Zhang WW, Rosen BP, Zhao FJ. 2016. Arsenic methylation in Arabidopsis thaliana expressing an algal arsenite methyltransferase gene increases arsenic phytotoxicity. Journal of Agricultural and Food Chemistry 64(13):2674-2681 DOI 10.1021/acs.jafc.6b00462.

Thomas P, Finnie JK, Williams JG. 1997. Feasibility of identification and monitoring of arsenic species in soil and sediment samples by coupled high-performance liquid chromatography-inductively coupled plasma mass spectrometry. Journal of Analytical Atomic Spectrometry 12(12):1367-1372 DOI 10.1039/a704149g.

Tsuda T, Babazono A, Ogawa T, Hamada H, Mino Y, Aoyama H, Kurumatani N, Nagira T, Hotta N, Harada M, Inomata S. 1992. Inorganic arsenic: A dangerous enigma for mankind. Applied Organometallic Chemistry 6(4):309-322 DOI 10.1002/aoc.590060403.

USEPA (United States Environment Protection Agency). 1989. Risk assessment guidance for superfund volume I: human health evaluation manual, Part A. Washington: Environment Protection Agency Publication.

USEPA. 2011. Exposure factors handbook. Washington: National Center for Environmental Assessment Publication.

USEPA. 2013. Regional screening level for chemical contaminants at superfund sites. Washington: Environment Protection Agency Publication.

Wang H, Shan Y, Sun ZR. 2016. The utilization and analysis of present market situation for Cordyceps sinensis. Research and Practice on Chinese Medicines 30(6):83-86 DOI 10.13728/j.1673-6427.2016.06.024.

Wei FS, Chen JS, Wu YY, Zheng CJ. 1991. Study on the background contents on 61 elements of soils in China. Environmental Science 12(4):12-19 DOI 10.13227/j.hjkx.1991.04.005.

Peer] reviewing PDF | (2020:07:51522:3:0:NEW 1 Feb 2021) 
440 Wei LL, Zhou Q, Xie CX, Wang J, Li J. 2016. Bioaccumulation and biomagnification of heavy metals in 441 three gorges reservoir and effect of biological factors. Environmental Science 37(1):325-334

442 DOI 10.13227/j.hjkx.2016.01.042.

443 Zhang SY, Williams PN, Luo JM, Zhu YG. 2017. Microbial mediated arsenic biotransformation in 444 wetlands. Frontiers of Environmental Science \& Engineering 11(1):1

445 DOI 10.1007/s11783-017-0893-y.

446 Zhang YJ, Li EW, Wang CS, Li YL, Liu XZ. 2012. Ophiocordyceps sinensis, the flagship fungus of china: 447 terminology, life strategy and ecology. Mycology 3(1):2-10

448 DOI 10.1080/21501203.2011.654354.

449 Zhao FJ, Ma JF, Meharg AA, Mcgrath SP. 2009. Arsenic uptake and metabolism in plants. New Phytologist 450 181(4):777-794 DOI 10.1111/j.1469-8137.2008.02716.x.

451 Zou ZW, Liu X, Zhang GR. 2010. Revision of taxonomic system of the genus Hepialus (Lepidoptera, 452 Hepialidae) currently adopted in China. Journal of Hunan University of Science \& Technology (Natural 453 Science Edition) 25(1):114-120 DOI 10.3969/j.issn.1672-9102.2010.01.025. 


\section{Figure 1}

Life cycle of Chinese cordyceps.

This figure was modified according to our previous study (Guo et al., 2018b). (A) The eggs came out of the insect host and started hatching. (B) The host larvae lived in the soil throughout the long-lasting larval stage. (C) The ascospores were germinated and released from the perithecia. (D) The ascospores infected the $4-5^{\text {th }}$ instar larvae under the ground. (E) The caterpillar filled with threadlike hyphae and formed the sclerotium. (F) The fungus grew out from the head and formed the stroma, Chinese cordyceps finally formed.

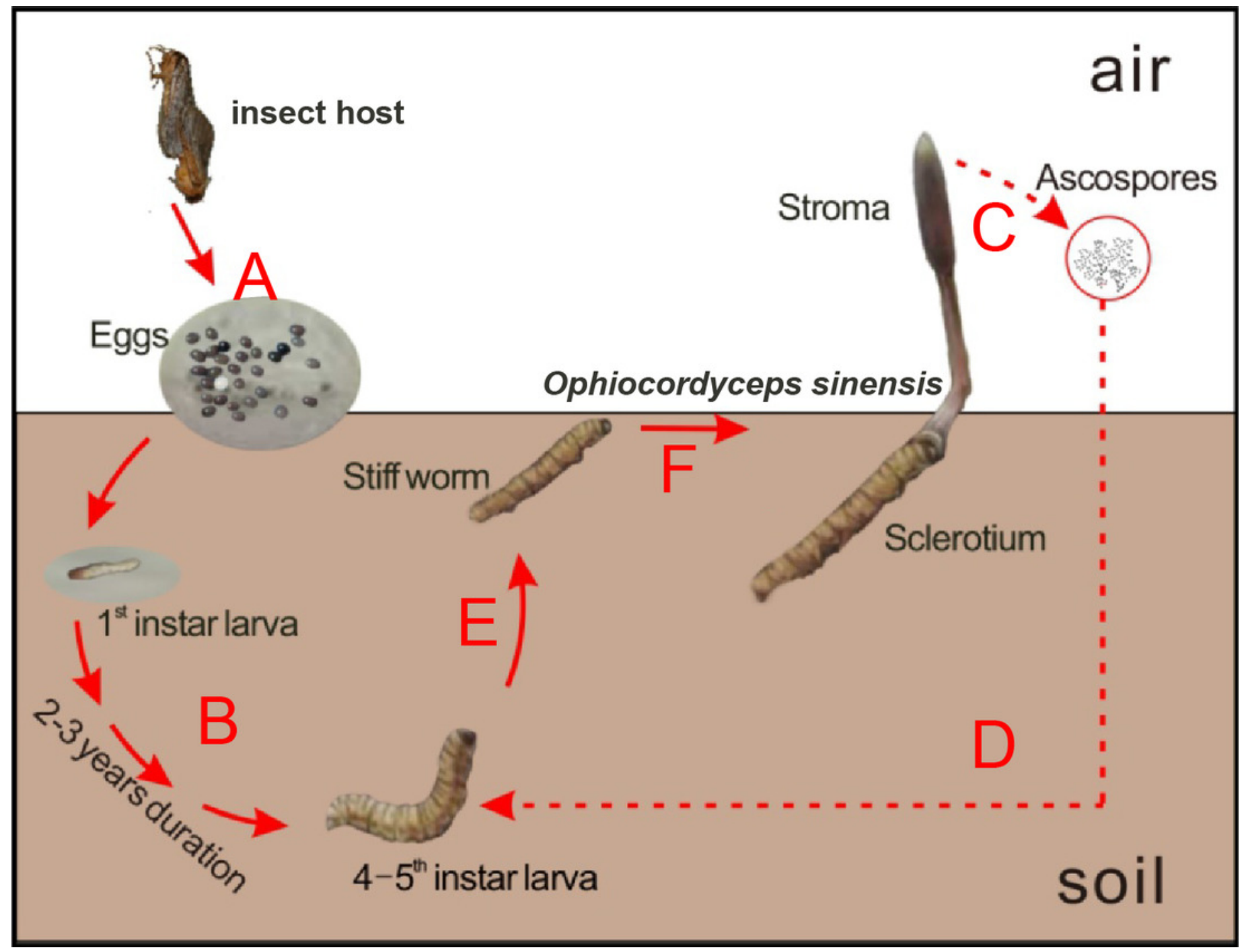




\section{Figure 2}

Chromatograms obtained in quantification by HPLC-ICP-MS.

(A) The mix standards of AsB, DMA, iAs"I, MMA and iAs ${ }^{\vee}$, at $50 \mathrm{ppb}$ of each arsenic species. (B) and (C) This was extracts of SC and ST collected from site B, respectively. The AAs"' and the other unknown peaks were overlapped. (D) and (E) This was oxidation products of the extracts of SC (B) and ST (C), the iAs" was transformed into iAs ${ }^{\vee}$ when the extracts was added with $\mathrm{H}_{2} \mathrm{O}_{2}$. (F) This was extract of soil sample collected from site $B$. (G) This was oxidation products of the extracts of soil sample (F). 


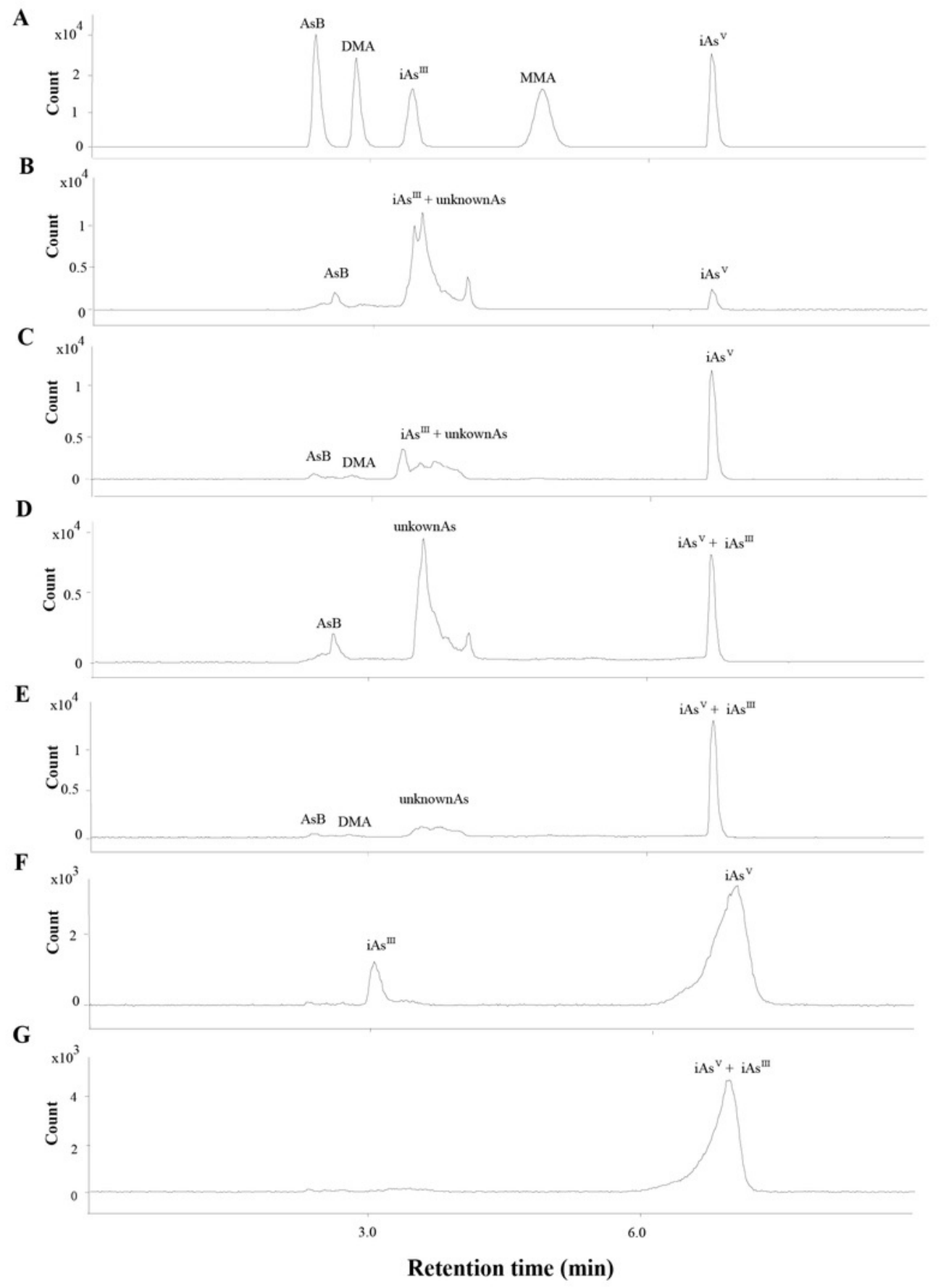




\section{Table $\mathbf{1}$ (on next page)}

Concentrations ${ }^{\mathrm{a}}$ of arsenic speciation ( $\left.\mathrm{mg} / \mathrm{kg}\right)(\mathrm{n}=15$ for $\mathrm{A}, \mathrm{B}, \mathrm{C}, \mathrm{n}=20$ for SC and ST). 


\begin{tabular}{|c|c|c|c|c|c|c|c|c|c|}
\hline \multirow{2}{*}{ Sample } & \multicolumn{5}{|c|}{ organic arsenic } & \multicolumn{3}{|c|}{ inorganic arsenic } & \multirow{2}{*}{ tAs } \\
\hline & $\mathbf{A s B}^{\mathbf{b}}$ & DMA & MMA & oAsU & total & As ${ }^{\text {II }}$ & $A s^{V}$ & total & \\
\hline A & $0.04 \pm 0.01$ & $0.03 \pm 0.02$ & nd & $3.75 \pm 0.25$ & $3.82 \pm 0.26$ & $0.62 \pm 0.15$ & $8.91 \pm 0.35$ & $9.54 \pm 0.21$ & $16.31 \pm 1.82$ \\
\hline $\mathrm{B}$ & $0.03 \pm 0.01$ & $0.04 \pm 0.01$ & nd & $2.06 \pm 0.26$ & $2.13 \pm 0.24$ & $4 \quad 0.74 \pm 0.07$ & $7.46 \pm 0.25$ & $8.20 \pm 0.18$ & $13.03 \pm 1.00$ \\
\hline $\mathrm{C}$ & $0.03 \pm 0.01$ & $0.04 \pm 0.03$ & nd & $2.88 \pm 0.29$ & $2.95 \pm 1.01$ & $0.66 \pm 0.03$ & $9.26 \pm 0.39$ & $9.92 \pm 0.37$ & $15.72 \pm 1.57$ \\
\hline $\mathrm{SC}_{\mathrm{A}}$ & $0.11 \pm 0.01$ & $\mathrm{nd}^{\mathrm{c}}$ & nd & $5.06 \pm 0.6$ & $5.17 \pm 0.6$ & $0.24 \pm 0.02$ & $0.09 \pm 0.01$ & $0.33 \pm 0.02$ & $5.50 \pm 0.58$ \\
\hline $\mathrm{SC}_{\mathrm{B}}$ & $0.10 \pm 0.01$ & nd & nd & $4.22 \pm 0.55$ & $4.32 \pm 0.55$ & $0.23 \pm 0.02$ & $0.09 \pm 0.00$ & $0.32 \pm 0.02$ & $4.64 \pm 0.54$ \\
\hline $\mathrm{SC}_{\mathrm{C}}$ & $0.13 \pm 0.02$ & nd & nd & $5.14 \pm 0.42$ & $5.27 \pm 0.43$ & $0.31 \pm 0.01$ & $0.1 \pm 0.01$ & $0.41 \pm 0.01$ & $5.68 \pm 0.44$ \\
\hline $\mathrm{ST}_{\mathrm{A}}$ & nd & nd & nd & 0.77 & 0.77 & 0.07 & 0.19 & 0.26 & 1.03 \\
\hline $\mathrm{ST}_{\mathrm{B}}$ & 0.01 & 0.01 & nd & 0.85 & 0.87 & 0.07 & 0.19 & 0.26 & 1.13 \\
\hline $\mathrm{ST}_{\mathrm{C}}$ & nd & nd & nd & 0.63 & 0.63 & 0.07 & 0.12 & 0.19 & 0.82 \\
\hline
\end{tabular}

2 Note:

3 a Concentrations were presented in $\mathrm{SC}_{\mathrm{A} / \mathrm{B} / \mathrm{C}}$ and soil $(\mathrm{A} / \mathrm{B} / \mathrm{C})$ as mean \pm standard deviation, concentrations were

4 presented in $\mathrm{ST}_{\mathrm{A} / \mathrm{B} / \mathrm{C}}$ as the average value; ${ }^{\mathrm{b}} \mathrm{AsB}, \mathrm{DMA}, \mathrm{MMA}, \mathrm{oAsU}, \mathrm{As}^{\mathrm{II}}, \mathrm{As}^{\mathrm{V}}$ and tAs were the abbreviation 5 of arsenobetaine, dimethylarsenic acid, monomethylarsonic acid, unknown organic arsenic, arsenite, arsenate, 6 and total arsenic, respectively; ${ }^{\mathrm{C}}$ not detected. 


\section{Table 2 (on next page)}

Non-carcinogenic average daily exposure doses of As in soil $(\mathrm{mg} / \mathrm{kg} \cdot \mathrm{d})$. 
1

\begin{tabular}{|c|c|c|c|c|c|c|c|c|}
\hline \multirow{2}{*}{ Site } & \multicolumn{2}{|c|}{$A D D_{\text {ing }}$} & \multicolumn{2}{|c|}{$A D D_{i n h}$} & \multicolumn{2}{|c|}{$A D D_{\text {dermal }}$} & \multicolumn{2}{|c|}{$A D D_{\text {total }}$} \\
\hline & Adults & Children & Adults & Children & Adults & Children & Adults & Children \\
\hline A & $2.8 \mathrm{E}-05$ & 2.0 E-04 & 3.2 E-09 & 5.6 E-09 & 7.0 E-10 & $3.2 \mathrm{E}-10$ & $2.8 \mathrm{E}-05$ & 2.0 E-04 \\
\hline B & $2.2 \mathrm{E}-05$ & $1.6 \mathrm{E}-04$ & 2.5 E-09 & $4.5 \mathrm{E}-09$ & $5.6 \mathrm{E}-10$ & $2.5 \mathrm{E}-10$ & $2.2 \mathrm{E}-05$ & $1.6 \mathrm{E}-04$ \\
\hline $\mathrm{C}$ & 2.7 E-05 & $1.9 \mathrm{E}-04$ & $3.1 \mathrm{E}-09$ & 5.4 E-09 & 6.7 E-10 & $3.0 \mathrm{E}-10$ & 2.7 E-05 & 1.9 E-04 \\
\hline
\end{tabular}

2

3

4

5

6

7

8

9

10 
Table 3 (on next page)

Carcinogenic average daily exposure doses of As in soil $(\mathrm{mg} / \mathrm{kg} \cdot \mathrm{d})$. 
1

\begin{tabular}{|c|c|c|c|c|c|c|c|c|}
\hline \multirow{2}{*}{ Site } & \multicolumn{2}{|c|}{$A D D_{\text {ing }}$} & \multicolumn{2}{|c|}{$A D D_{i n h}$} & \multicolumn{2}{|c|}{$A D D_{\text {dermal }}$} & \multicolumn{2}{|c|}{$A D D_{\text {total }}$} \\
\hline & Adults & Children & Adults & Children & Adults & Children & Adults & Children \\
\hline $\mathrm{A}$ & 9.6 E-06 & 1.7 E-05 & 1.1 E-09 & 4.8 E-10 & $2.4 \mathrm{E}-10$ & 2.7 E-11 & 9.6 E-06 & $1.7 \mathrm{E}-05$ \\
\hline $\mathrm{B}$ & 7.7 E-06 & $1.3 \mathrm{E}-05$ & 1.7 E-09 & $3.8 \mathrm{E}-10$ & $1.9 \mathrm{E}-10$ & $2.2 \mathrm{E}-11$ & 7.7 E-06 & $1.3 \mathrm{E}-05$ \\
\hline $\mathrm{C}$ & $9.2 \mathrm{E}-06$ & $1.6 \mathrm{E}-05$ & $1.1 \mathrm{E}-09$ & 4.6 E-10 & $2.3 \mathrm{E}-10$ & $2.6 \mathrm{E}-11$ & 9.2 E-06 & $1.6 \mathrm{E}-05$ \\
\hline
\end{tabular}

2

3

4

5

6

7

8

9

10

11

12

13

14

15

16

17

18

19

20 
Table 4 (on next page)

Index of carcinogenic risk and non-carcinogenic risk. 
1

2

\begin{tabular}{lcccccccccc} 
& \multicolumn{1}{c}{ Site } & Groups & $H Q_{\text {ing }}$ & $H Q_{\text {inh }}$ & $H Q_{\text {dermal }}$ & $H I$ & $C R_{\text {ing }}$ & $C R_{\text {inh }}$ & $C R_{\text {dermal }}$ & $C R_{T}$ \\
\hline 4 & A & Adults & 0.09 & $2.59 \mathrm{E}-05$ & $2.32 \mathrm{E}-06$ & 0.09 & $1.4 \mathrm{E}-05$ & $4.69 \mathrm{E}-12$ & $3.58 \mathrm{E}-10$ & $1.4 \mathrm{E}-05$ \\
5 & & Children & 0.66 & $4.54 \mathrm{E}-05$ & $1.05 \mathrm{E}-06$ & 0.66 & $2.5 \mathrm{E}-05$ & $2.06 \mathrm{E}-12$ & $4.05 \mathrm{E}-11$ & $2.5 \mathrm{E}-05$ \\
6 & B & Adults & 0.07 & $2.07 \mathrm{E}-05$ & $1.85 \mathrm{E}-06$ & 0.07 & $1.1 \mathrm{E}-05$ & $3.74 \mathrm{E}-12$ & $2.86 \mathrm{E}-10$ & $1.1 \mathrm{E}-05$ \\
7 & & Children & 0.52 & $3.63 \mathrm{E}-05$ & $8.38 \mathrm{E}-07$ & 0.52 & $2.0 \mathrm{E}-05$ & $1.65 \mathrm{E}-12$ & $3.23 \mathrm{E}-11$ & $2.0 \mathrm{E}-05$ \\
8 & C & Adults & 0.09 & $2.49 \mathrm{E}-05$ & $2.23 \mathrm{E}-06$ & 0.09 & $1.4 \mathrm{E}-05$ & $4.52 \mathrm{E}-12$ & $3.45 \mathrm{E}-10$ & $1.4 \mathrm{E}-05$ \\
9 & & Children & 0.63 & $4.38 \mathrm{E}-05$ & $1.01 \mathrm{E}-06$ & 0.63 & $2.4 \mathrm{E}-05$ & $1.99 \mathrm{E}-12$ & $3.90 \mathrm{E}-11$ & $2.4 \mathrm{E}-05$ \\
\hline
\end{tabular}

10

11

12

13 